\title{
Integración al Aula: Una Estrategia Para la Intervención y Evaluación, Guiada a Través del Uso de las Nuevas Tecnologías de Intervención (TICs)
}

\section{Integration Into the Classroom: A Strategy for Intervention and Assessment Guided Through the Use of New Intervention Technologies (ICTs)}

\author{
Jorge Eslava-Cobos y Jennifer Ricaurte-Perdomo \\ Instituto Colombiano de Neurociencias
}

\begin{abstract}
Este artículo informa acerca de un proyecto de integración al aula regular de niños con diversas discapacidades, guiado a través de estrategias virtuales (TICs). Se describe un curso guía, su recurso tecnológico para la planeación de la intervención y se evalúa la aplicabilidad, eficacia y utilidad de las TICs, su aceptación por parte de los docentes y el sistema en general; la utilidad de la retroalimentación para la evaluación que genera el instrumento y la factibilidad de implementar proyectos de investigación-acción a través de las TICs. Se exponen las conclusiones como una respuesta afirmativa a este tipo de apoyo discutiendo las implicaciones de las mismas.
\end{abstract}

Palabras Clave: integración, TIC, estrategias de intervención, evaluación.

This article provides information about a project concerning the integration of children with several disabilities into the traditional classroom guided by virtual strategies (ICTs). A guide course is described as well as its technological resource for the intervention planning. Applicability, efficiency and usefulness of ICTs are assessed, as well as their acceptance not only by teachers but the education system as a whole. The usefulness of feedback for evaluation that the instrument generates and the feasibility of implementing action research projects through ICTs are also assessed. Conclusions are presented as a positive answer to this type of support and their implications are discussed.

Keywords: integration, ICT, intervention strategies, assessment.

\section{Antecedentes y Marco Conceptual}

Desde el año 2000 se viene desarrollando una experiencia en la que se utilizó la investigaciónacción como herramienta metodológica para la capacitación de maestros en la integración de niños con discapacidad al aula regular. La experiencia fue altamente exitosa, pero el proceso de capacitación era largo y dispendioso; ello lo hacía poco eficiente en términos de costo-efectividad (Eslava \& Ricaurte, 2000). Posteriormente en una nueva fase, el objetivo consistió en verter esa metodología en una estrategia que fuese más eficiente y costo-efectiva, encontrándola en las nuevas Tecnologías de Información y Comunicación (TICs).

En esa nueva fase en donde se generó un diseño apoyado en las nuevas tecnologías de comunicación

\footnotetext{
Jorge Eslava Cobos, Instituto Colombiano de Neurociencias. Jennifer Ricaurte Perdomo, Instituto Colombiano de Neurociencias.

La correspondencia relativa a este artículo deberá ser dirigida a Jorge Eslava Cobos, Carrera 64 \# 98-26, Bogotá, Colombia. E-mail: neurociencias@cable.net.co

Reconocimiento a los estudiantes y padres de familia de cada una de las instituciones que participaron en el proyecto.
}

(TICs), se mantenía la estrategia de intervención planteada en el PFPD original mencionado anteriormente, basado en la investigación-acción; que según Zuber-Sherritt (2007), debe ser vista como una herramienta de trabajo más que como la sola búsqueda del conocimiento y como un proceso cíclico iterativo de acción y reflexión sobre y en la acción; buscando conceptualizaciones y generalizaciones de lo sucedido en dicha acción.

Esta TIC hizo parte del curso-guía para la integración de estudiantes con dificultades al aula regular, con apoyo de multimedia, que incorporó además color, imágenes y facilitó el registro, seguimiento y transporte de datos, el acceso a la comunicación a través de nuevos medios tecnológicos, obteniendo aprendizajes guiados por esta; pero lo más importante, accediendo al nuevo lenguaje audiovisual. Este nuevo lenguaje determina una manera novedosa de comprender, aprender y dar a conocer posturas, logros y propuestas, cumpliendo así con los requisitos básicos de las TICs acorde a lo expresado por muchos autores, entre ellos Vera (2003), no sin olvidar otro de los objetivos centrales de ese curso: la integración (o inclusión) de niños y niñas con dificultades y discapacidades al aula regular. 
Al hablar de este eje temático, la inclusión, no puede olvidarse que hoy en día ha sido aceptada como estrategia válida de intervención y ha evolucionado su concepto hasta convertirse en estrategia prioritaria, de aceptación casi universal. Desde ella -partir del reconocimiento y aceptación a la diferencia- se pretende ofrecer igualdad de condiciones y oportunidades para acceder a los bienes de la comunidad incluyendo la oferta educativa no segregada, pero es allí en donde empiezan a surgir las inquietudes de quienes se enfrentan a esta situación. Algunos de esos interrogantes que se han puesto en evidencia son: ¿Quién es un niño con discapacidad? ¿Qué puedo hacer como pedagogo con una persona con algún tipo de limitación? ¿Qué pasa con el rendimiento en los aprendizajes académicos clásicos? ¿A quién le correspondería el manejo de un niño así? ¿Qué sucede con los otros niños que acompañan el proceso? ¿Cuáles son los recursos con los que se cuenta, no solo en formación sino dentro de la misma institución académica en cuanto a espacios, recursos humanos, económicos? ¿Cómo cumplir con los estándares para determinar los logros? ¿Qué apoyos ofrece el sistema?

Estos -y muchos otros- interrogantes asaltan al educador que acepta el reto de extender su práctica hacia los niños y niñas con dificultades especiales sensoriales, cognitivas, de comportamiento, motrices, en cualquier ámbito académico; y es por esto que se diseñó el curso de integración con apoyo de las TICs para que los profesionales encargados de un proyecto de inclusión, lograran hacer de una manera ordenada, clara y concisa la planeación, registro y evaluación de la intervención para así lograr el análisis de lo ocurrido en todo el proceso y poder entonces responder a esas preguntas; generando en lo posible propuestas específicas.

La presencia de estas dificultades e interrogantes no puede hacernos perder de vista un elemento central: la Escuela. Esta es hoy, de manera preferente, el lugar propicio para el desarrollo integral del niño. Es, para los niños y niñas de hoy, uno de los principales entornos para que estos se apropien del conocimiento. Les ofrece además, el mejor ambiente para facilitar la interacción social -de importancia vital-dado el papel estructurante que este intercambio tiene para el sujeto, que lo conduce al desarrollo de habilidades propias que no son innatas sino que deben ser aprendidas en el acto mismo de la comunicación y la interacción. Es así entonces, cómo el niño a medida que se educa va adaptándose a la cultura, adquiriendo el lenguaje, costumbres, ideas y normas morales de la sociedad. Todo ello requiere reconocer como funciones educativas: (a) el progresivo incremento y apropiación del conocimiento y de la comprensión imaginativa del estudiante sobre el mundo en que vive, tanto por lo que se refiere a las posibilidades que le ofrece como a las responsabilidades que a él mismo le corresponden.; (b) a futuro, propiciar el desarrollo de toda la independencia y autosuficiencia de que sea capaz, enseñándole lo necesario para que pueda responder a las necesidades de su propia vida, ya sea controlando, dirigiendo o alcanzando metas.

Ahora bien, algunos de esos niños, conseguirán fines con facilidad, otros tendrán dificultades a las que podrán hacer frente y otros tendrán mayores problemas para superarlas requiriendo apoyo permanente. Todos los alumnos en mayor o menor medida tienen dificultades, ya sean comunes, ya específicas y especiales, entendidas como lo que cada estudiante requiere para realizar progresos individualmente (Cabanillas \& Dotto, 2003). El hecho de que algún niño tenga mayores dificultades y necesidades, no lo excluye de la anterior argumentación. Se desprende entonces, que también todos los niños tienen derecho a los bienes, servicios y beneficios que el cuerpo social les ofrece.

Para todos los niños con y "sin" dificultades, las funciones de la educación se proyectan entonces hacia dos polos: (a) la adaptación, socialización y endoculturación, función eminentemente humana en donde no hay intención explícita ya que el hombre está inserto en una sociedad que le impone ciertas pautas culturales a las cuales el individuo debe adaptarse para asegurar su conservación y continuidad; (b) la instrucción formal, caracterizada principalmente por la presencia de intención y sistematización mediante la participación de un educador, un educando y un contenido de tipo renovador, innovador y transformador de acuerdo a la necesidad de cambio de la sociedad y la cultura (Nassif, 1984 citado en Cabanillas \& Dotto, 2003).

Las anteriores consideraciones confieren a la integración escolar un sentido de imperativo ético actual que a pesar del largo camino que ha recorrido, aún es un concepto que debe romper paradigmas. Entre ellos, la concepción de la escuela como una institución homogeneizadora para evolucionar hacia una institución comprensiva, atendiendo así a todos los alumnos en sus características particulares, con el fin de garantizar el derecho a la educación que tienen todos los individuos. 
Pese a que lo anterior es claro para muchas instituciones educativas, aún genera incertidumbre en los docentes y comunidad académica, el hecho de recibir un niño con necesidades educativas especiales. Para muchos, el primer interrogante es cómo poder -desde su quehacer pedagógico- alcanzar las metas de aprendizaje y socio culturales pre-establecidas por las normas, si estos alumnos llegan ya con unas dificultades marcadas por la misma discapacidad que los hace especiales. Para otros, la inclusión al aula de un niño "patológico" genera grandes temores de que pueda "empeorar", e incluso morir por falta de preparación del maestro en esa excepcionalidad. Aún otros, temen que los otros niños -los "normales"- puedan verse afectados en su rendimiento o incluso "contagiarse" de algunos elementos de ese niño "especial". Y otros más... por cualquier otra razón... que sustentan así esa larga la lista de prevenciones.

No obstante, como se verá más adelante en Resultados, la mayoría de esas prevenciones demuestran que solo eran eso y se derrumban cuando el maestro y la escuela asumen el reto.

Desde el ordenamiento jurídico, actualmente, en Colombia, la Constitución (reformada en 1991) y la ley, consagran estos derechos. Así por ejemplo, la Ley General de Educación (Ley 115 de 1994), en su artículo 46, plantea la educación para personas con limitaciones o capacidades excepcionales como parte integrante del servicio público educativo, para lo cual los establecimientos (directamente o mediante convenio) deben desarrollar acciones pedagógicas y terapéuticas que permitan el proceso de aprendizaje y relación con sus pares y otros que conforman la comunidad.

Esta educación se fundamenta en los principios de integración social y educativa, desarrollo humano, oportunidad y equilibrio, y soporte específico. La norma igualmente señala que en el Proyecto Educativo Institucional (PEI), se especificarán las adecuaciones curriculares, organizativas y pedagógicas, así como los recursos físicos, tecnológicos, y de capacitación y formación de la comunidad educativa que sean necesarios para la integración. (Decreto 2082, 18 de noviembre de 1996). La mayoría de las Naciones en Latinoamérica, viven realidades similares.

Sobre estas dos realidades, a saber, los desarrollos de la estrategia de capacitación de docentes en integración al aula de niños con dificultades hacia estrategias y técnicas inmersas en las TICs, y la evolución de la integración al aula regular como impera- tivo moral reflejado cada vez con mayor intensidad a la práctica cotidiana, se construye y desarrolla el trabajo que aquí se informa: "La integración al aula regular: una estrategia desde ambientes virtuales de intervención y evaluación".

Los objetivos de este trabajo fueron:

1. Evaluar la aplicabilidad, eficacia y pertinencia de una herramienta basada en las TICs diseñada para apoyar al Docente en la integración de niños y niñas con dificultades al aula regular.

2. Evaluar la aceptación por parte de los componentes del sistema (principalmente la escuela y los docentes), de las TICs.

3. Evaluar la utilidad de las TICs como instrumento generador de información que ofrezca una retroalimentación útil y permita una autoevaluación razonablemente objetiva.

4. Constatar la factibilidad de implementar proyectos de investigación-acción apoyados en el uso de las TICs.

\section{Método}

\section{Muestra}

Se realizó un muestreo por conveniencia dentro de las escuelas públicas de Bogotá. Se seleccionaron tres escuelas y dentro de ellas se seleccionaron seis casos, cinco tipos de dificultad y cuatro aulas, de manera que representaran un amplio espectro de aplicación del instrumento como lo muestra la Tabla 1.

Los criterios de inclusión fueron:

1. Escuelas que tuviesen niños con discapacidades definidas que requirieran apoyo para su integración al aula regular.

2. Escuelas que manifestaran -a través de sus directivos y el/los docentes que dirigirían los casos- su deseo de vincularse al proyecto y su compromiso de llevarlo a cabo.

\section{Instrumento}

Sobre los antecedentes anteriormente descritos, se diseñó -con apoyo de las TICs - el instrumento denominado "CursoGuía para la Integración de Estudiantes con Dificultades al Aula Regular", material editado -en la primera versión- en conjunto entre el Instituto Colombiano de Neurociencias y Editorial Santillana (Eslava, Mejía \& Ricaurte, 2003).

Este es un material que guía "de la mano" (y de allí el nombre del icono Lázaro, por analogía con los lazarillos), al docente y a la escuela misma, sobre los elementos que se deben incluir en el diagnóstico, la detección de dificultades, la planeación del proceso de integración, el registro de acciones y la evaluación de los estudiantes con dificultades en el aula y del proceso mismo. Busca llevar al docente y a la comunidad educativa, a identificar situaciones concretas de dificultad o áreas específicas de déficit, ayudarlo a organizar -a partir del pensamiento estratégico- un inventario realista de las carencias pero también de las fortalezas y oportunidades, a buscar información y reflexionar acerca de alternativas pedagógicas que permitan la inclusión, a diseñar e implementar indicadores que permitan hacer seguimiento a los logros del proceso y recoger 
Tabla 1

Perfil de los sujetos intervenidos

\begin{tabular}{llll}
\hline Nombre de la Institución & $\mathrm{N}^{\circ}$ de Estudiantes Elegidos & Grado escolar & Área de dificultad \\
\hline S J N & 1 & Niña de $7^{\circ}$ Bto. & Motricidad fina y Habla \\
& 1 & Niño de $3^{\circ}$ Pria. & Cognitiva
\end{tabular}

V A

J F

TOTALES
2
Niñas de $5^{\circ}$ Pria.

Niña de $4^{\circ}$ Pria.

Niño de $4^{\circ}$ Pria.

3 grados de

primaria

1 grado de
Afectivo-Emocional

Cognitivo-Autismo

Cognitivo

5 tipos de dificultad

bachillerato

retroalimentación para corregirlo y redirigirlo; en concordancia con lo expuesto por Navas y Guerras (2002). El instrumento convoca a todos los profesionales que intervienen sobre el niño o caso, a trabajar interdisciplinariamente, liderados por quien tiene el niño directamente a su cargo, tanto en la adecuación del currículo, como en el diseño de estrategias de intervención y la solución de imprevistos cotidianos de una manera innovadora; todo ello con el fin de corroborar lo propuesto desde la investigación-acción tal y como lo enuncia Fals (2007), en cuanto a que no se trata de una experiencia personal, sino que supone siempre un contexto social; llevando a obtener datos más cercanos a la realidad -una realidad más armónica con la comunidad académica. El equipo del Instituto reconoce de manera explícita que no hay una única manera de abordar la integración escolar; esta requiere ajustes constantes a partir de la singularidad de cada experiencia, buscando que la escuela ofrezca espacios amables y eficaces que incluyan a todos los miembros.

El curso guía, se acompaña de tres elementos: un libro impreso con documentos de apoyo y dos carpetas con material de orientación y de ejemplo (caso modelo). Viene en un CD con un formato que facilita el registro de los datos y el seguimiento del proceso planteado. Este material está diseñado como un módulo semivirtual, interactivo y de autoformación que permite al docente y a todas las personas involucradas capacitarse para el manejo de los estudiantes con dificultades o de bajo rendimiento en sus aulas. Recoge cada uno de los objetivos buscados en los diferentes proyectos: capacitación, evaluación, procesos de reflexión, pensamiento estratégico, procesos de innovación, procesos de seguimiento y evaluación a través de indicadores, sistematización de las experiencias y publicación de resultados.

El curso guía para la integración de estudiantes al aula regular, solicita de manera directa involucrar desde un comienzo a los diferentes participantes de la comunidad educativa, por lo que el diseño contempla cinco sectores: institución, docentes, curso, estudiante en el colegio, estudiante en la familia. Se busca que en primera instancia se analice a fondo la información preliminar, que de alternativas para la implementación de un proyecto educativo innovador con metas, estrategias y acciones que faciliten integrar al estudiante, seguido de la consecución de cambios importantes al interior de la institución escolar a partir del seguimiento a través de la aplicación de indicadores de logro. Todo este material, se imprime a medida que se desarrolla el proyecto pues el mismo instrumento así lo solicita al usuario.

Los segmentos principales del instrumento -que son presentados de manera secuencial- son los siguientes:

Fase 1. Diagnóstico. En esta se identificaron los posibles estudiantes a trabajar y, con el apoyo de una encuesta que viene en la TIC, se establecieron las dificultades discriminadas en ocho capítulos (visual, auditivo, motor grueso, motor fino, comunicación, perceptual-gnósico, intelectual y afectivo-emocional). Este perfil pedagógico, permitió elegir el sujeto que requería mayor atención y participación. (Ver Figura 1)

Fase 2. Información sobre el caso. En primer lugar se hizo una Descripción General del alumno elegido, especificando información referida a la Institución, los Docentes, el Curso, el Estudiante en el Colegio y el Estudiante en la Familia. En segundo lugar se realizó esta descripción, pero mucho más detallada en los mismos cinco capítulos, denominada Presentación del Caso. Esta fase permitió delimitar el problema que interfería en el proceso de integración del estudiante elegido. (Ver Figuras 2 y 3 )

Fase 3. Planeación del proceso. Dentro de esta fase se diferenciaron algunos subprocesos: Delimitación Estratégica, Metas e Indicadores de Logro, Estrategias y Registro de Acciones (Ver Figura 4, 5, 6, 7). Primero se realizó la Delimitación Estratégica, para lo cual se aplicó una matriz DOFA a cada uno de los cinco capítulos, es decir, se identificaron las debilidades, oportunidades, fortalezas y amenazas. Luego, el segundo y tercer paso dentro de la fase de Planeación, consistió en el establecimiento de metas e indicadores de logro y las acciones a realizar; para esto, cada institución elegía una o dos metas por cada uno de los capítulos 
Diagnóstico de dificultades

Gráfico de dificultades de MARIANA MARIANA

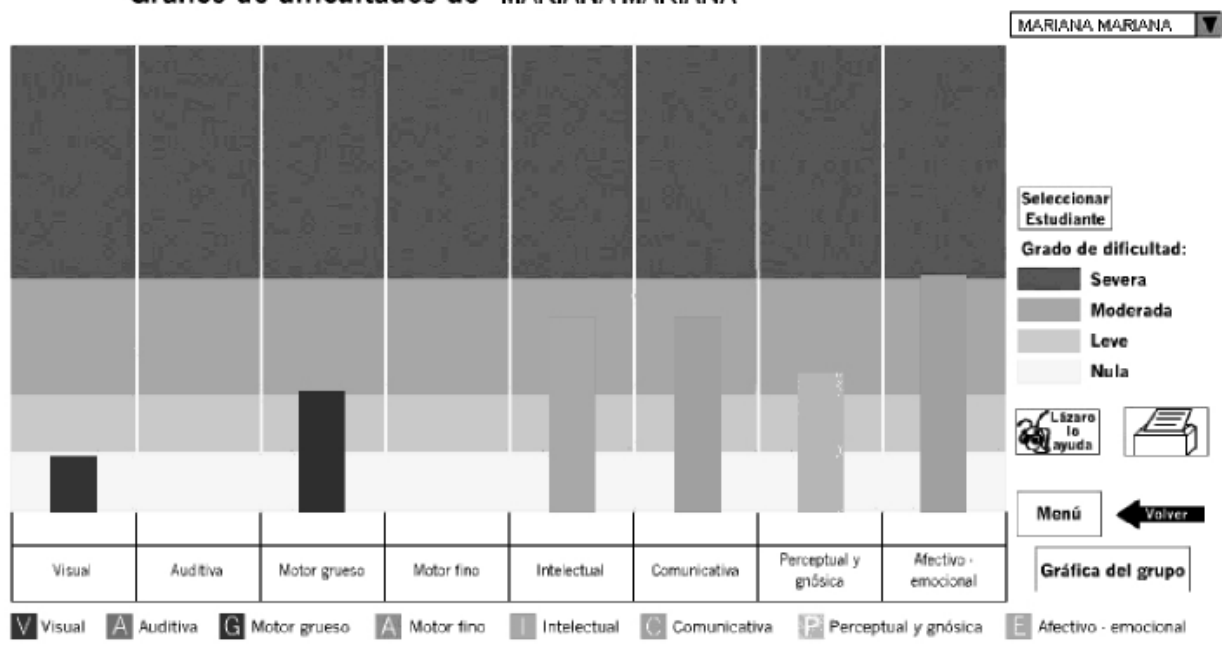

Figura 1. Fase 1: Diagnóstico. Ejemplo del perfil de dificultades de uno de los sujetos.

trabajados en el curso-guía (Institución, Curso, Docentes, Estudiante en la Escuela, Estudiante en la Familia), acompañados de los indicadores que facilitarían el seguimiento y evaluación de las acciones ejecutadas. Estas metas e indicadores se fraccionaron en tres segmentos (cada uno correspondiente a un trimestre del año lectivo) de manera que se podía obtener retroalimentación periódica que permitiera redireccionar el proceso de acuerdo a los resultados parciales.

Fase 4. Ejecución de acciones. El docente ejecuta lo planeado. Se apoya en los impresos que ha hecho de las fases anteriores.

Fase 5. Retroalimentación y resultados. El software captura las metas que el mismo docente se fijó en la Fase 3 como denominadores de los indicadores de logro y luego -cuando ya se han ejecutado las acciones- el docente evalúa los progresos conseguidos en esa meta en particular. El instrumento presenta -por default-los denominadores de los indicadores de logro que había capturado; el docente digita entonces lo conseguido, que el sistema captura como numerador de los indicadores de logro. Con ello, el software presenta porcentajes de avance. Esta información se presenta tanto de manera numérica, porcentual, como de manera gráfica. En este último caso, contra una abscisa que le permite identificar si estos logros fueron los esperados o por encima o debajo de lo planeado y en qué magnitud aproximada (Ver Figuras 8 y 9). Como antes se anotó, estas retroalimentaciones pueden obtenerse y visualizarse para cada uno de los tres segmentos parciales. De igual manera, el software presenta un consolidado general final que obra a manera de evaluación final del proceso.

\section{Procedimiento}

Luego de la entrega de los Curso Guía, cada institución educativa eligió un equipo de trabajo delegando un responsable para cada caso. Esta docente lideraba la planeación e intervención sobre el/los caso/s seleccionado/s. Era igualmente, la encargada de diligenciar la información en el software con base en lo recogido por todos los participantes.

Paralelamente, las docentes fueron acompañadas por uno de los investigadores, quien cumplía tres funciones básicas:

1. Acompañar el proceso para recoger información sobre aplicabilidad, receptividad, utilidad, eficacia, tropiezos, defectos, etc. Esta información se recogió en algunos elementos estructurados, como se detallan más adelante, y también como observaciones no estructuradas.

2. Coordinar los encuentros de saberes para la interlocución a diferentes niveles: al interior de los grupos de trabajo, entre los distintos estamentos de la escuela, reuniones de diversos grupos y diversas escuelas.

3. Apoyar el proceso de integración con sugerencias de acciones puntuales o bibliografías específicas. Esta última intervención sin embargo, se mantuvo como "último recurso" pues se buscaba indagar por la aplicabilidad de la TIC de manera autónoma. No obstante, las consideraciones éticas obligaron a este tipo de intervención ocasionalmente.

\section{Instrumentos de Medición de Resultados}

La recolección de información para evaluar los resultados de la investigación se hizo -como anteriormente se señaló- tanto con observaciones no estructuradas como con elementos estructu- 


\section{MARIANA MARIANA}

\section{Presentación del caso}

El estudiante en la escuela

Patgina 1 de 6

\section{1. ¿Cómo fue el rendimiento en antos anteriores?}

En ed especial adquirí hábilos para adaptarse a la escolaridad, en Col Alba Edison esturo un ańo, en esta institución en 1 y 2 fué muy buena aprendio a leer y adquino habilidades sotlales y comunicativas, en 3 bajo por fallas a nivel cognitwo(re solución problemas)leng.

2. En el periodo escolar actual cómo ha sido su rendimiento académico general

Trabaja en clase, atiende, pero no cumple con tareas, lo cual retrasa el proceso ya que se pierde continuidad.

3. Especifique sus dos mayores dificultades A nNel cognitiro(resolucion de problemas, análisis) lenguaje a nivel sintáctico,pragmálic)

4. Rendimiento en las asignaturas

Español

Tiene buen renimiento en la parte mecánicadectura, escritura)

parle formal, pero anivel de contenido falla en comprensión,

análisis, oranización del điscurso a nivel escrito coherencia y cohe

Sociales

Su renimiento e variable memoriza, capta y en ocaciones da

respuestas acordes al tema de manera coherente.

Matemáticas

Desarrolla las operciones a nivel mecánico, dificultad en analisis.

Ciencias

Su renimionto o variable memoriza, captayen ocaciones da respuestas acordes al tema de manera coherente. $8 \mathrm{e}$ interesa porel tema de los animales y los planelas.

Figura 2. Fase 2: Información sobre el caso. Ejemplo de la información detallada sobre el caso de uno de los sujetos.

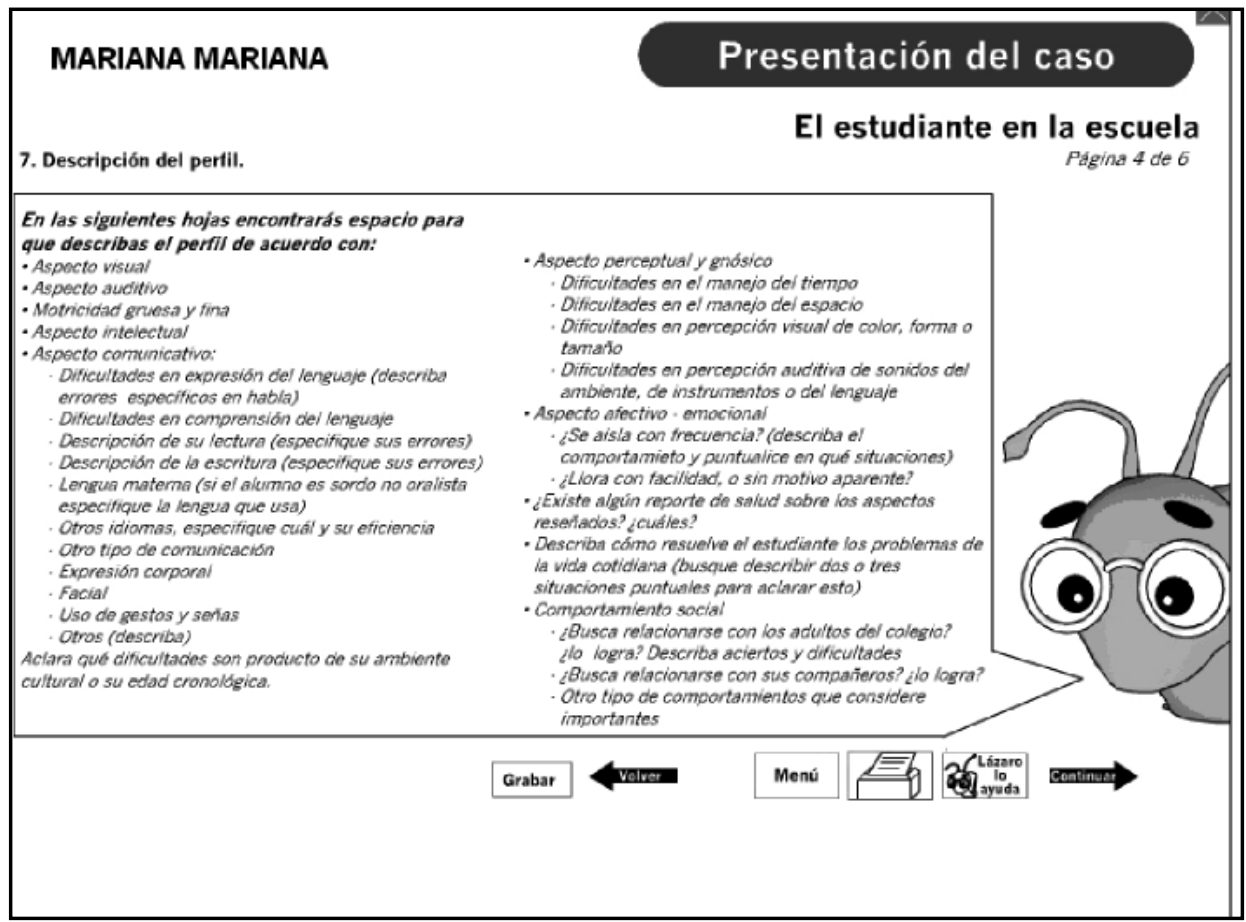

Figura 3. Fase 2: Información sobre el caso. Al presentar el caso, se solicita al docente entrar en detalle al describir el perfil del estudiante. 


\section{Delimitación estratégica}

Los docentes

Oportunidades:

El ap oyo de la Docente de educación física, en el trabajo de exploración de habilidades deportivas, la aprobación por perte de la rectora para cons eguir una docente de artes en jornada contraria, la experiencia y el entusiasmo de la docente de inglés y curso 2, para implementar el programa de culti̛os hidropónicos con los niñ́us integrados.

Amenazas:

Las adaptaciones curriculares, significarían un trabajo extra para el docente y estarian en proceso de implementación, con las consecuentes dificultades que esto pudiera acarrear.

Fortalezas:

La disposición de la docente de curso y de la fonoaudióloga como docente de apopo del programa.

Debilidades:

La Docente manifiesta su necesida de adquirir más capacitación en tomo al tema de la integración para optimizar su manejo, pese a su gran disposición y la experiencia que ha adquirido en estos ańos

¿Ha encontrado estrategias para controlar las debilidades y las amenazas? SI

¿Cuáles?

Abrir un espacio con la profesora, para trabajar sobre las adpataciones curriculares y sobre cual duda con respecto a estas, invitar a las profesoras a seminarios y charlas de actualización sobre integración y temas relacionados.

Grabar Menú de Menú
sección Menú

Figura 4. Fase 3: Planeación del proceso. Delimitación estratégica.

\section{Metas e indicadores de logro}

\section{El curso}

Meta 1 Un currículo flexible. humanizante $y$ con apren dizajes siqnificativos que de respuesta a las necesidades. habilidades e intereses del niño(a) con NEE.
Indicador de logro para
todo al periodo de trabajo

Figura 5. Fase 3: Planeación del proceso. Metas e indicadores. 


\section{Estrategias}

\section{La institución escolar}

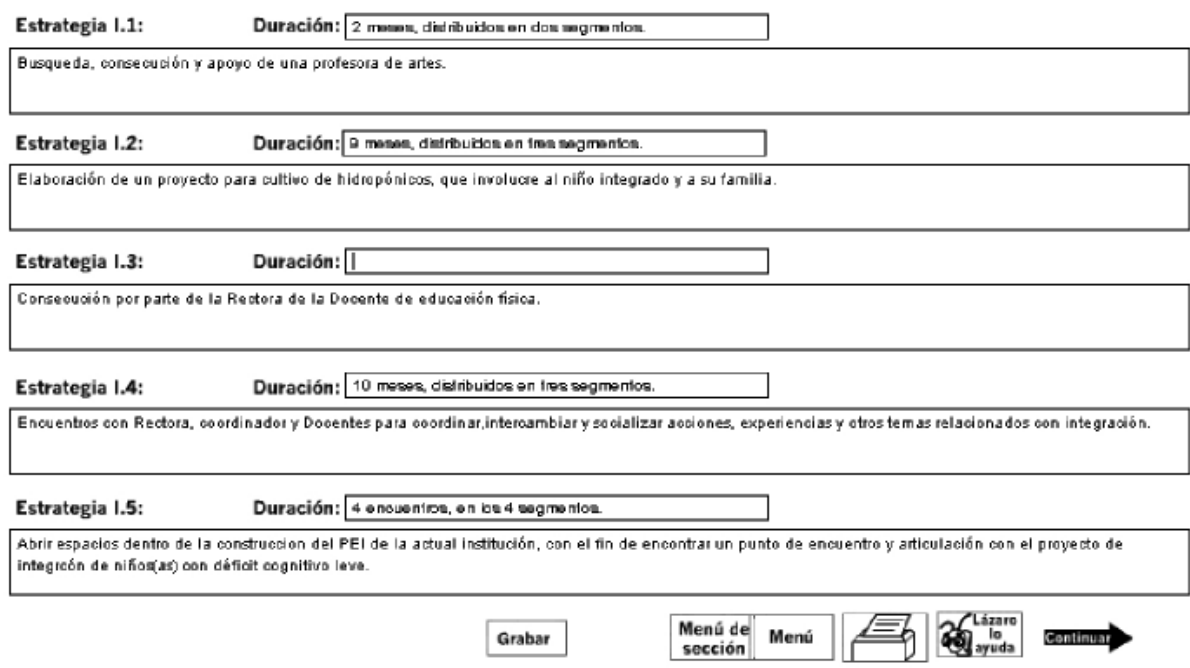

Figura 6. Fase 3: Planeación del proceso. Estrategias.

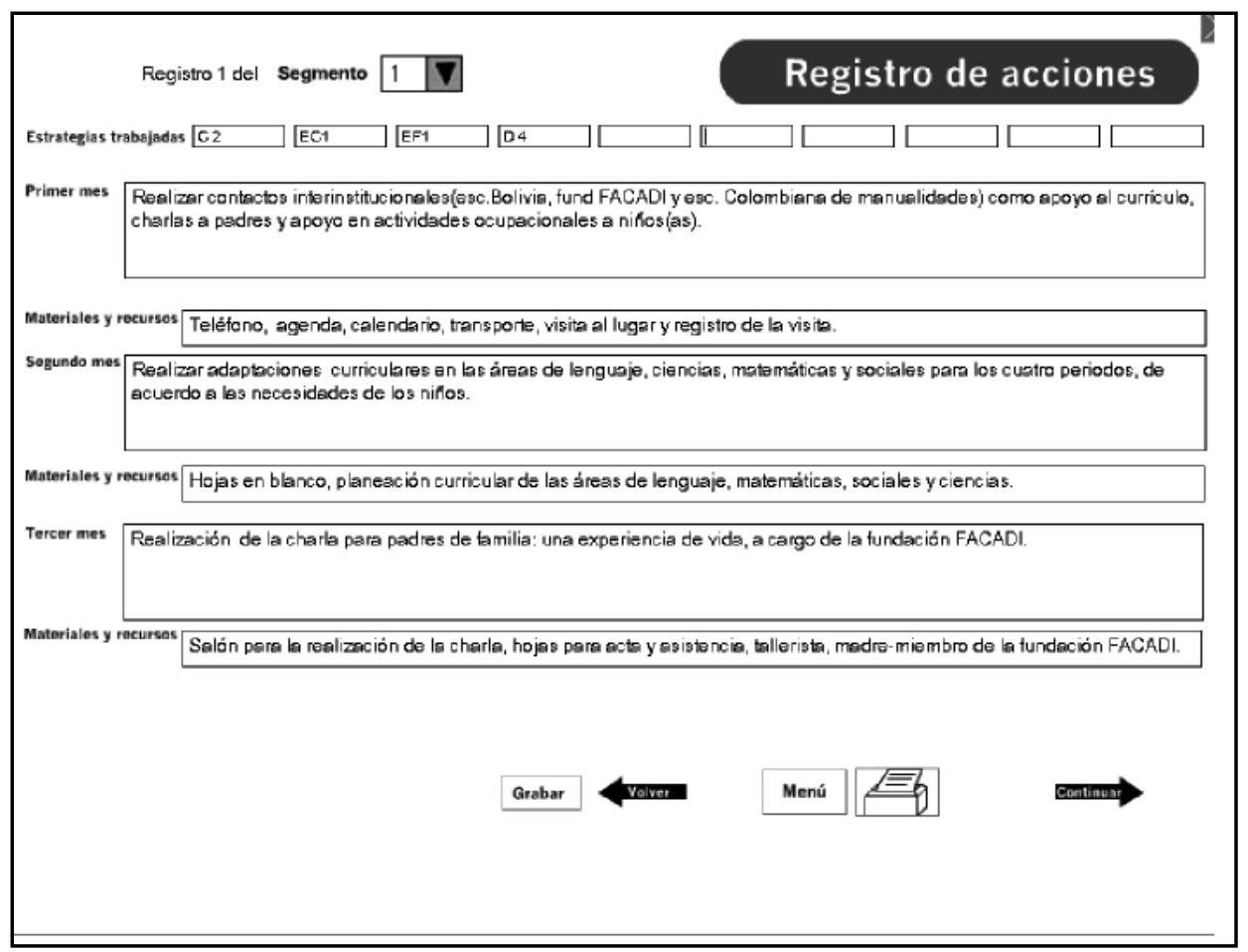

Figura 7. Fase 3: Planeación del proceso. Registro de acciones. 


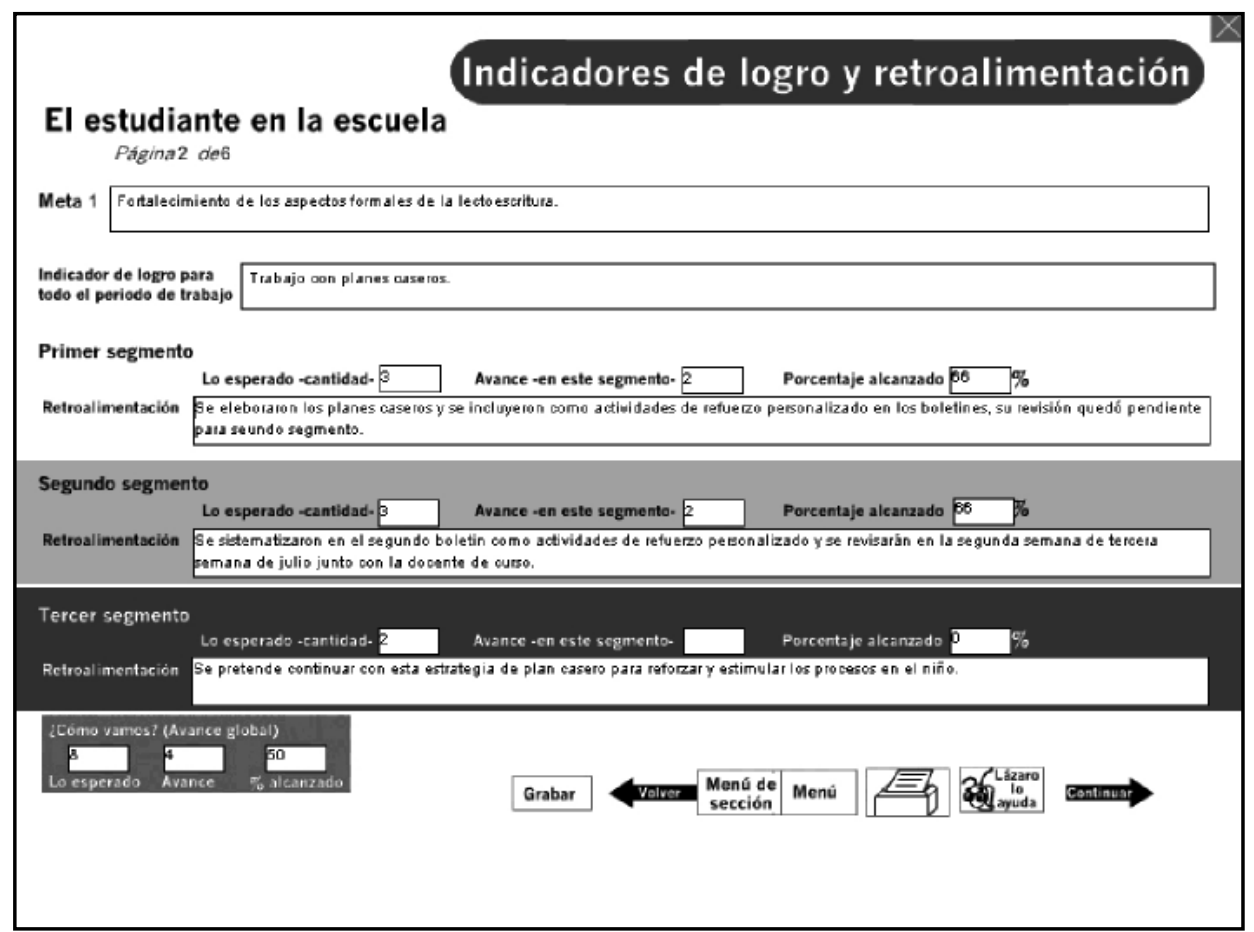

Figura 8. Fase 5: Retroalimentación y resultados. Indicadores de logro y retroalimentación: El docente captura y el sistema arroja resultados en porcentaje.

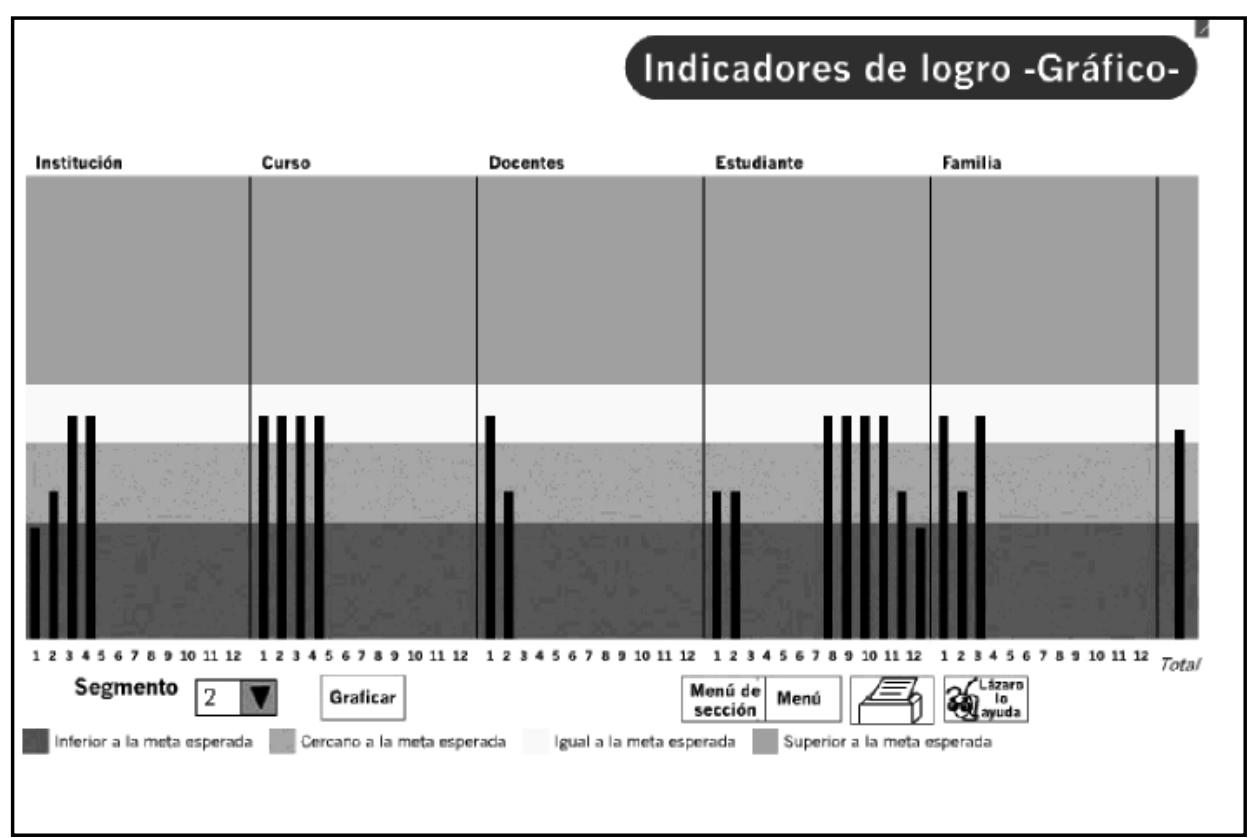

Figura 9. Fase 5: Retroalimentación y resultados. Indicadores de logro y retroalimentación: El sistema arroja resultados en porcentaje y los grafica. En este ejemplo se observa los resultados del seguimiento al segundo segmento de tiempo del proyecto. 
rados. Estos últimos se recogieron desde dos perspectivas: desde el interior y el exterior del instrumento.

Indicadores Intrinsecos al Instrumento.

Como se señaló en la Fase 5 del instrumento (ver Figuras 8 y 9), el software permite evaluar los resultados del proceso de integración/inclusión en términos del cumplimiento de metas preestablecidas por el propio docente. Para los efectos de esta investigación, las retroalimentaciones parciales se tomaron como indicadores de proceso, en tanto que la evaluación final se tomó como indicadores de resultado de la efectiva integración del sujeto elegido.

Indicadores Externos al Instrumento.

Indicadores. Se diseñaron una serie de indicadores para evaluar los resultados del proyecto general de intervención. Estos fueron: compromiso de los centros educativos seleccionados, compromiso de la comunidad educativa, inclusión del programa dentro de las actividades académicas, número de estudiantes integrados, áreas académicas involucradas, creación de experiencias innovadoras, mejoramiento de algunos aspectos de la calidad educativa, mejoramiento de los procesos de evaluación, incorporación de los resultados de la investigación al proyecto educativo institucional (PEI) de las escuelas.

Desde lo Pedagógico. En conjunto con los docentes se evaluó el saldo pedagógico en cada uno de los cinco capítulos (la institución, el curso, los docentes, los estudiantes, las familias), para cada uno de los proyectos.

\section{Resultados}

\section{Aplicabilidad}

Los tres centros educativos lograron la aplicación total del instrumento sin ninguna dificultad.

\section{Aceptación de la Experiencia Innovadora}

Los indicadores externos al instrumento tuvieron resultados cercanos al $100 \%$, con excepción del Compromiso de la Comunidad Educativa que apenas logró una aceptación de $67 \%$. En lo positivo, se destaca el entusiasmo por nuevos enfoques aportados por la TIC, en especial, el pensamiento estratégico como herramienta para facilitar la planeación, y la investigación-acción como estrategia para enfrentar el reto de la integración/inserción de niños con dificultades. A partir de esta última, surgieron proyectos de aula de gran interés, como por ejemplo "Gobierno Escolar y Producción de Textos", demostró que un maestro puede plantear estrategias pedagógicas para el apoyo a estudiantes con dificultades afectivo emocionales, y por otro lado, "adaptaciones curriculares de elementos que ya están siendo aplicados por las docentes de artes y educación física" que han favorecido a los niños integrados con déficit cognitivo. Estos se han apo- yado a través de la ejecución de talleres de artes e hidropónicos ${ }^{2}$.

\section{Trabajo en Equipo}

De las tres instituciones, una de ellas tuvo dificultad para integrar al trabajo los representantes de la comunidad educativa. Las acciones realizadas fueron de manera aislada, aunque con buenos aportes para el proyecto. Las otras dos, por el contrario, obtuvieron un trabajo coordinado y con acciones específicas que les facilitó la interlocución y análisis de la situación pedagógica de los niños integrados y de la capacitación en el tema a través de la TIC. En todas las instituciones educativas, fue posible la inclusión del programa dentro del cronograma general, lo que facilitó la ejecución de las estrategias con sus correspondientes acciones. Sin embargo, en una de ellas, esta incorporación de la estrategia integradora no ocurrió como se esperaba, hecho este atribuido a las múltiples funciones del responsable que le impidieron hacerlo a tiempo. Como valor agregado se destaca la conformación de un equipo colaborativo para la interlocución permanente -en este caso- del proceso de integración al aula pero extrapolable a otros contextos, pues permite tomar el principio de organización al interior del grupo para alcanzar los objetivos propuestos.

\section{Inserción de la TIC en el Currículo y en el PEI}

Todos optaron por desarrollar el proceso desde las seis áreas básicas del currículo (Ciencias, Lenguaje, Artística, Educación Física, Sociales, Matemáticas). Involucraron a los docentes que las lideran o coordinan y definieron pautas para el seguimiento de logros o evaluación de las mismas.

El indicador más bajo de toda la investigación (33\%) fue el referido a la inclusión de la estrategia integradora dentro del marco general del Proyecto Educativo Institucional (PEI) de las escuelas. En Colombia está consagrada una amplia autonomía de las instituciones educativas (dentro de ciertos límites y directrices), que se plasma en el PEI, el cual es redactado por el gobierno escolar y revisado periódicamente. Se pretendía que los buenos resultados del

\footnotetext{
La palabra "hidropónico" (de hidros, agua, y pones, trabajo) designa un tipo de botánica que merecería llamarse "aeropónico", ya que su elemento más destacado no es tanto el riego como la creación de un entorno general, y especialmente lumínico, cuya finalidad es proporcionar a cualquier tipo de planta un medio idóneo para desarrollarse y florecer, sin requerir de la tierra.
} 
proyecto indujeran al gobierno escolar a abrazar la estrategia de integración dentro de sus PEIs, hecho este que solo ocurrió en el 33\%.

\section{Efectiva Integración de los Sujetos Elegidos}

En el 50\% de la muestra se lograron avances muy positivos en las diferentes áreas (académica, social, familiar, personal, comunicativa), de acuerdo a lo señalado por los indicadores internos del instrumento (ver Figuras 8 y 9). En el 34\%, los logros académicos fueron menores; los sociales, familiares y afectivos fueron apreciables en algunos sujetos pero también pobres en otros. En el restante 16\% no se logró una efectiva integración al aula regular.

\section{Retroalimentación y Autoevaluación}

La totalidad de las instituciones manejaron apropiadamente la retroalimentación surgida de los indicadores de logro (ver Figuras 8 y 9). Este seguimiento de indicadores favorecía el tomar medidas oportunas para el cambio de estrategias o refuerzo de acciones para la consecución del resultado, o por el contrario, el desistir un camino elegido, y además determinar los posibles ajustes a la herramienta virtual. Entre estas medidas oportunas, se destaca particularmente las modificaciones en los métodos de evaluación de los niños/as. En una de las instituciones, por ejemplo, el desempeño durante las actividades en los talleres de artes e hidropónicos, permitía evaluar de mejor manera los conceptos adquiridos y su aplicación a un evento real. En otra, se diseñaron nuevos retos por parte de la docente de educación física. De todo ello, surgió la sistematización de un boletín específico para la evaluación académica.

\section{Investigación-Acción a Través de las TICs}

Para todas las instituciones, la experiencia inicial con el instrumento fue compleja. Los docentes no tenían experiencia en el uso de este tipo de herramienta, lo que generó temor de incorporar la tecnología en su quehacer pedagógico cotidiano. Por otro lado, la inexperiencia en el manejo de sistemas, llevó a todos los docentes a realizar inicialmente grabaciones ineficientes del material. Fue necesaria una capacitación breve sobre copias de seguridad por parte del área de sistemas. Por lo demás, el instrumento fue fiel a su misión de convertirse en una herramienta amigable. Con el paso del tiempo, a medida que desarrollaban el programa, todos los docentes se sintieron seguras y confiadas en su manipulación. Al final, todos concluyeron que la aplicación de estos ambientes virtuales crea una ruptura tal en el quehacer pedagógico que los llevó a cuestionarse sobre la organización de sus aulas de sistemas y la distribución de los recursos con los que contaba la institución.

Superadas estos tropiezos elementales iniciales, el hecho de que todas las instituciones educativas lograran la aplicación total del instrumento sin ninguna dificultad, aseguró la exitosa implementación de la metodología de investigación-acción vista como herramienta de trabajo. Ello debido a que -al incluir el instrumento un apoyo (Lázaro) que "guiaba de la mano al docente" en las diferentes fases secuenciales del proceso-la exitosa implementación de las etapas del software, conducía casi inevitablemente al exitoso desarrollo del proyecto de investigación-acción. Se presentaron sin embargo, interesantes cuestionamientos. En primera instancia, los docentes líderes, a pesar de conocer el método científico y los pasos a seguir, nunca los habían aplicado para la labor diaria. No consideraban los pasos del método científico aplicables a (y en ocasiones ni siquiera compatibles con) el quehacer pedagógico cotidiano. El mismo hecho de solicitarles los elementos requeridos para el diagnóstico, generó inquietudes en torno a la observación clínica. Fue posible sin embargo, llegar a la conclusión de que no se buscaba rotular a los niños, de manera que lo importante era establecer cuáles eran las características de la dificultad que estaban interfiriendo con su desempeño académico para con ello poder elegir las acciones a seguir. Todo lo anterior confirma nuevamente uno de los aspectos que define la investigación-acción y es el cambio de actitudes tanto en los académicos como en las comunidades; se acumula el conocimiento, pero con una causa justa; se descubren leyes que ya seguramente la gente había descubierto y venía practicando sin saber que se trataba de principios universales (Fals, 2007).

\section{Desde lo Pedagógico}

Una perspectiva novedosa de presentación de resultados es la de "saldos pedagógicos", asimilables de alguna manera al seguimiento antes- después de cohortes (la institución, el curso, los docentes, el niño, la familia), sobre la base de las observaciones no estructuradas -aunque en ocasiones apoyadas en los elementos estructurados. Unos fragmentos 
de "saldos pedagógicos" de uno de los casos más favorable son (Caballero, 2006):

1. La Institución: Se logra el respaldo de directivas, profesores y padres de familia para la aprobación de acciones y consecución de recursos -incluyendo los económicos. Se establecieron contactos interinstitucionales que favorecieron el desarrollo del proyecto de integración.

2. El Curso: Se logró la adaptación del currículo en las áreas de matemáticas, sociales, ciencias y lenguaje. Con el taller de sensibilización se logró la elección del compañero monitor.

3. Los Docentes: Los docentes han participado en la coordinación de las adaptaciones curriculares, pero ha sido difícil la implementación de las mismas, al parecer-aunque no lo expresan-por temor y desconocimiento del tema.

4. El Niño: Cada uno de los niños integrados ha obtenido logros en diferentes áreas. El niño es hábil en la elaboración de algunos trabajos de artes y en la venta de los mismos. Con la niña se ha hecho énfasis en favorecer la socialización que ha mejorado, pero aún se le dificultan los procesos de análisis y síntesis de la información, requiriendo apoyo continuo.

5. La Familia: Es evidente la diferencia de respuestas de las dos familias. La de la niña se ha interesado y comprometido con la propuesta del colegio. Con el niño ha sido más difícil, la madre es poco colaboradora y asiste irregularmente a las actividades.

\section{Análisis de Resultados y Conclusiones}

\section{Evaluar la aplicabilidad, eficacia y pertinencia de una TIC diseñada para apoyar al docente en la integración de niños y niñas con dificultades al aula regular.}

La evaluación del proyecto se realizó con base en los resultados de los casos individuales e institucionales.

En lo institucional, todas las escuelas involucradas lograron aplicar el instrumento. Luego de una etapa inicial de cierta confusión con aspectos técnicos puntuales del manejo del software, este se incorporó a la rutina y su aplicación fue fluida.

En lo individual, $50 \%$ de los casos lograron una exitosa y plena integración al aula regular, $34 \%$ una integración apenas regular y ello solo en algunos aspectos y $16 \%$ no lograron ser integrados. Considerando que todos estos casos presentaban una "patología" importante, que tradicionalmente venía siendo manejada desde estrategias segregadoras, se considera confirmado que el instrumento es pertinente y eficaz. La investigación no incluyó valoraciones econométricas pero la simple afirmación de que estos niños hubiesen sido manejados en el esquema clásico desde instalaciones y facilidades de educación especial, en tanto que en este proyecto se manejaron en, desde y con los recursos convencionales de un aula regular; nos permite afirmar que la relación costo-efectividad de esta estrategia es altamente favorable.

El éxito pleno en 50\% y parcial en 34\% se torna aún más significativo cuando se interpreta desde la apenas incipiente aparición de la estrategia integradora y se recuerda que esta solo ha tomado significativa fuerza en Colombia en el último quinquenio. Esa realidad crea un tejido de incertidumbre al interior de cualquier entidad educativa, que induce diversas reacciones; se encuentran aquellos que en mayor o menor grado están de acuerdo con las disposiciones sociales y de ley, otros que la aprueban siempre y cuando no les corresponda directamente y por último aquellos que rechazan rotundamente el reto y solo lo asumen porque se sienten obligados a ello.

El $50 \%$ de los casos en los que la respuesta fue parcial o nula es un campo fértil para la indagación posterior a fin de determinar hasta que punto ese nivel de fracaso es atribuible al instrumento mismo o señala simplemente los límites de la integración. En el primer caso, procede por supuesto un trabajo continuado para mejorarlo o la decisión radical de utilizar un instrumento distinto. El segundo caso hace referencia a un interrogante mas profundo: reconocido ya el imperativo ético de la integración y establecida su factibilidad, frente a situaciones de mayor complejidad, ¿tiene límites la estrategia integradora? ¿Cuáles son esos límites? ¿Es pertinente fijarlos a priori?

Evaluar la aceptación por parte de los componentes del sistema (principalmente la escuela y los docentes) de la TIC.

Puede afirmarse que hubo un muy buen nivel de aceptación de la TIC por parte de la escuela y los docentes. Así lo afirman los indicadores externos al instrumento (todos cercanos al 100\%), el hecho de que todas las escuelas optaran por desarrollar el proceso con la TIC desde las seis áreas básicas del currículo (Ciencias, Lenguaje, Artística, Educación Física, Sociales, Matemáticas), y los saldos peda- 
gógicos reseñados en Resultados referentes a la institución, el curso y los docentes.

Es clara sin embargo una relación directa entre magnitud de la exposición y aceptación. Aquellos docentes que lideraban los procesos y que por ello mismo tenían una alta exposición al instrumento mostraron una alta aceptación, en tanto que los que apoyaron el proceso de manera marginal mostraron dificultad al momento de implementar las acciones surgidas de la aplicación de la TIC, al parecer -aunque no lo expresan- por temor y desconocimiento.

Este hallazgo es llamativo si se tiene en cuenta que -dentro del concierto Latinoamericano- Colombia muestra una de las tasas más bajas de masificación de las TICs. En nuestra opinión, sugiere que los actores del sistema están preparados para aceptarlas e implementarlas, y de hecho ávidos por ellas, y señala una realidad que los responsables administrativos deben recoger para capitalizarla como importante oportunidad.

\section{Evaluar la utilidad de la TIC como instrumento} generador de información que ofrezca una retroalimentación útil y permita una autoevaluación razonablemente objetiva.

La identificación de instrumentos de evaluación y retroalimentación en el contexto de la integración/ inclusión al aula regular de niños y niñas con discapacidad es un asunto particularmente complejo. De un lado, el hecho mismo de partir de una realidad de discapacidad hace inviable e inválida la evaluación "como a todos los demás chicos". Aún desde posturas teóricas homogenizadoras que defienden las evaluaciones "Standard para chicos Standard", el reconocimiento de "este chico/a especial" descarta la evaluación con estrategias pedagógicas homogéneas. Por otro lado, el hecho de que se trata de un niño o niña con discapacidad crea la tentación de aceptar progresos muy discretos o incluso nulos. No existen -a nuestro conocimiento- instrumentos de evaluación o retroalimentación que atiendan a esas complejidades.

La TIC evaluada emplea una forma de evaluación que -en sus orígenes- se inspira en dos elementos no relacionados. De un lado, estrategias surgidas del pensamiento empresarial (Navas \& Guerra, 2002) que buscan definir metas e indicadores de proceso y de resultado. De otro, el pensamiento Vigotskiano de "zonas de desarrollo potencial" (Vigotsky, 2001) -en especial las próximas- que anima a tratar de identificar metas posibles dentro de una realidad conocida. Esa realidad es sin embargo con frecuencia esquiva porque todos tenemos gran facilidad para identificar las carencias (que suele desembocar en interminables letanías de plañidera) pero tenemos en cambio gran dificultad para identificar los recursos con los que sí contamos. La TIC evaluada anima al docente a conseguir una identificación integral de sus recursos y dificultades a través de un elemento surgido del pensamiento estratégico -la aplicación de una matriz DOFA (debilidades, oportunidades, fortalezas, amenazas) (González, 1994).

Sobre estas bases, el docente identifica los recursos y dificultades a los que se enfrenta, se fija sus propias metas $\mathrm{y}-\mathrm{a}$ ellas- les establece indicadores de proceso. La TIC, a través de un software amigable, lo guía en ese proceso. Posteriormente captura estos datos como denominadores para el cálculo de indicadores y los presenta después "por default". El docente implementa entonces las acciones que diseñó y luego recoge los resultados de esas acciones que son capturados por el software como numeradores y con ello se establecen los avances (si los hay) en términos de indicadores parciales (o acumulativos) de proceso. Todo este material es presentado amigablemente de manera numérica y gráfica. Con estos elementos, el docente dispone de retroalimentación que le permita redirigir acciones y evaluaciones razonablemente objetivas de resultados.

Las evaluaciones y retroalimentaciones surgidas de la TIC (ver Figuras 8 y 9) pudieron ser aplicadas en todos los casos estudiados; permitieron determinar el éxito o fracaso del proceso (como se expuso en párrafos anteriores), y tuvieron gran aceptación de parte del docente (hecho este de particular relevancia dada la situación reciente de conflicto que se vivió en Colombia ante la determinación del Ministerio de Educación de evaluar a los docentes lo que generó grandes movimientos de reivindicación sindical). Destacamos sin embargo como de mayor relevancia, el hecho de que esta forma de evaluación permite afrontar las complejidades en la evaluación de niños y niñas con discapacidad al aula regular a las que arriba se ha hecho referencia.

Constatar la factibilidad de implementar proyectos de investigación-acción a través una TIC.

La investigación tiene diversos usos en un amplio rango que va desde la clásica producción de conocimiento en el ámbito científico hasta la pesquisa de información para propósitos utilitarios 
puntuales en el ámbito comercial. Cada uno de estos usos escoge la estrategia metodológica que mejor se acomoda a sus fines (Elliot, 1992).

Hace unos años, el Instituto publicó una experiencia utilizando la investigación-acción como herramienta metodológica para la capacitación de maestros en la integración de niños con discapacidad al aula regular (Eslava \& Ricaurte, 2000). Esta metodología igual puede aplicarse a otros propósitos, como por ejemplo, al diseño e implementación de proyectos de aula. Ello por cuanto la investigación-acción, en estos contextos, puede concebirse como una herramienta práctica de intervención, de fácil implementación para recoger información pertinente, diseñar procesos de una manera ordenada y bien fundamentada y hacerle seguimiento a los resultados obtenidos para redireccionar acciones y evaluar los logros finales.

Del artículo arriba reseñado es importante citar a Lawrence Stenhouse (citado en Stufflebeam \& Shinkfield, 1985), quien señala que la clave del planteamiento consiste en la aplicación de la investigación a la educación recurriendo al juicio del profesor. Afirma que la mejoría de la enseñanza se basa en el desarrollo del arte del profesor -a través de la investigación- y no en la adopción por su parte de unos procedimientos uniformes escogidos entre alternativas en competencia. Para este autor la investigación es una "indagación sistemática y autocrítica". Como indagación se halla basada en la curiosidad y en un deseo de comprender; pero se trata de una curiosidad estable, no fugaz, sistemática en el sentido de hallarse respaldada por una estrategia. Lo anterior, bien conocido por los investigadores clínicos, es en cambio con frecuencia novedoso (e incluso rodeado de un espantador halo de misterio) para los maestros de las escuelas regulares.

No obstante, Stenhouse (citado en Stufflebeam \& Shinkfield, 1985), confiere gran importancia a la relación profesor-investigador enunciando que la investigación para resultar útil a los profesores exige que estos comprueben en sus aulas sus implicaciones teóricas, pues respalda más la práctica docente la investigación que, o bien determina hipótesis que pueden ser comprobadas en sus aulas, o ilustra casos particulares que cabe contrastar con la experiencia. Cualquiera de las dos situaciones, puede proporcionar un estímulo a la planificación de la indagación en las aulas. El presente trabajo llevó a la práctica esta actividad de investigación por parte de los docentes y evaluó sus resultados.

Ahora bien, la necesaria participación de investigadores que sugiere Stenhouse (citado en
Stufflebeam \& Shinkfield, 1985), requiere recursos humanos, logísticos y financieros importantes, que suelen no estar disponibles. Ello conduce a la interrogante: ¿Será factible implementar proyectos de investigación-acción a través una TIC que mejoren la relación costo-efectividad de esa estrategia?

Los hallazgos sugieren que sí es factible, tal y como se lee en la sección Resultados de este documento: Superados estos tropiezos elementales iniciales, el hecho de que todas las instituciones educativas lograran la aplicación total del instrumento sin ninguna dificultad, aseguró la exitosa implementación de la metodología de investigación-acción vista como herramienta de trabajo. Ello debido a que -al incluir el instrumento un apoyo (Lázaro) que "guiaba de la mano al docente" en las diferentes fases secuenciales del proceso- la exitosa implementación de las etapas del software, conducía casi inevitablemente al exitoso desarrollo del proyecto de investigación-acción.

Se debe llamar la atención sin embargo, al hecho de que en el desarrollo del proyecto se incluyeron diversos momentos de interlocución entre los docentes participantes de la experiencia. Es posible que en esos espacios hayan surgido apoyos importantes cuya ausencia (de no haber existido esas interlocuciones), mermara de alguna manera los buenos resultados en este sentido. Queda para el futuro determinar si estos buenos resultados se mantienen en contextos totalmente autónomos.

Se concluye que la investigación-acción vista como una herramienta de trabajo más que un medio para la producción de conocimiento $-\mathrm{y}$ aplicada a través de una TIC- facilita la organización de proyectos innovadores que hacen posible, en un número importante de casos, la efectiva integración al aula de niños y niñas con necesidades educativas especiales, y probablemente también aplicable a otros contextos. Tal y como lo dice Grundy (2007), la valoración de la diversidad está integralmente conectada con la importancia de la participación, por ende lo que recuerda la investigación acción es que la diversidad de análisis y la diversidad de interpretación es crucial si se va a investigar la realidad para cambiarla. Por tal razón, la participación y la experticia de cada integrante del equipo contribuyen al crecimiento y el desarrollo no solo personal, sino del proyecto mismo a través de la reflexión, la planeación y la evaluación. En suma, la asociación de saberes benefició a las escuelas y al desarrollo profesional de los maestros. 


\section{Discusión}

Desde la perspectiva del resultado pedagógico del proyecto de investigación que aquí presentamos, creemos pertinente afirmar que la integración al aula regular es una estrategia apropiada frente al estudiante con necesidades educativas especiales. No significa ello que sea la única vía posible o que esté llena de virtudes o exenta de dificultades o tropiezos, pero parece indiscutible que es, hoy en día, una de las principales alternativas, si no la primera.

Otro saldo interesante es el referido a la sistematización de la información en Educación, con énfasis especial en la gestión de procesos educativos, líneas base de fortalezas y debilidades, metas e indicadores de logro y sistemas automatizados de evaluación de progresos y cumplimiento de metas.

Nos apoyamos en el hecho de que la investigación-acción, vista como una herramienta de trabajo más que un medio para la producción de conocimiento, facilita la organización de proyectos innovadores que aportan estrategias -no solo para la continuidad y sostenibilidad en el tiempo de las mismas o duplicación de experiencias-sino también para crear nuevas expectativas hacia el cambio de fundamentos teóricos referidos a los procesos de enseñanza-aprendizaje y de evaluación. Estos proyectos de investigación-acción, apoyados en nuevas herramientas de TICs, crean soportes específicos para la búsqueda de nueva información y para apoyar a maestros que inicialmente estén temerosos de asumir retos con niños que tienen dificultades especiales.

Reiteramos el hecho que para dar respuesta a tantos interrogantes que surgen en torno a la integración al aula, es indispensable realizar proyectos de innovación pedagógica. Las tres instituciones escolares participantes, en su último encuentro, concuerdan en que la TIC evaluada en este proyecto es una herramienta novedosa y útil. Aspiramos a que su aplicación futura conduzca a consolidar proyectos de aula que consigan hacer realidad la meta de facilitar la integración al aula regular de niños y niñas con necesidades educativas especiales para bien de ellos mismos, de sus compañeros "normales", de sus maestros, del sistema educativo y -en una concepción más amplia que contribuya a crear comunidades más justas, incluyentes, felices, eficientes y respetuosas y valorativas de la diversidad-de la sociedad toda. Consideramos que ese objetivo en este proyecto se logró, y desde tres perspectivas, como lo anotó una de las docentes en la última reunión de saberes: (a) la creación de metas a partir de adaptaciones curriculares; (b) la implementación de varios programas a través de una TIC buscando logros específicos acordes a las necesidades de cada estudiante; y (c) el cambio de actitud hacia la diferencia.

\section{Referencias}

Cabanillas, G. \& Dotto, A. (2003). El aspecto social de la integración escolar de niños con discapacidad visual: Interacciones. Argentina: Profesorado en Educación y Rehabilitación para Discapacitados Visuales.

Decreto 2082 del 18 de noviembre de 1996. Atención educativa para personas con limitaciones o con capacidades o talentos excepcionales. Colombia.

Elliot, J. (1992). La investigación-acción en educación. Madrid: Morata.

Eslava, J., Mejía, L. \& Ricaurte, J. (2003). Curso guía: Integración de estudiantes con dificultades al aula regular. Bogotá: Santillana.

Eslava, J. \& Ricaurte, J. (2000). La investigación como herramienta de capacitación de docentes para la integración al aula de niños con dificultades. Psykhe, 9(1), 27-37.

Fals, O. (2007). Investigación acción participativa: Donde las aguas se juntan para dar forma a la vida. Revista Internacional Magisterio. Educación y Pedagogía, 26, 11-14.

González, J. A. (1994). Gerencia estratégica, planeación y gestión -teoría y metodología-. Bogotá: Editorial Legis.

Grundy, Sh. (2007). Efecto liberador de la investigación acción participativa y la acción participante. Revista Internacional Magisterio. Educación y Pedagogía, 26, 22-25.

Ley 115 de 1994. Sistema de Educación Nacional. Colombia.

Navas, J. E. \& Guerras, L. A. (2002). La dirección estratégica de la empresa. Teoría y aplicaciones ( $3^{\mathrm{a}}$ ed.). Madrid: Citivas.

Stufflebeam, D. \& Shinkfield, A. (1985). Evaluación sistemática. Guía teórica y práctica. Barcelona: Paidós.

Vera, A. (2003). Las tecnologías de información y comunicaciones (Tic) en la docencia universitaria. Theoría: Ciencia, Arte y Humanidades, 12, 109-118.

Vigotsky, L. S. (2001). Pensamiento y lenguaje. Barcelona: Paidós.

Zuber-Sherritt, O. (2007). Desarrollo profesional y del liderazgo en educación superior a través del aprendizaje en la acción (Action Learning) y de la investigación acción. Revista Internacional Magisterio. Educación y Pedagogía, 26, 30-33. 